\title{
RELATIVE PAYOFFS AND HAPPINESS: AN EXPERIMENTAL STUDY*
}

\author{
Gary Charness \\ Department of Economics \\ Universitat Pompeu Fabra, Barcelona \\ and \\ Department of Economics \\ University of California, Berkeley
}

\author{
Brit Grosskopf \\ Department of Economics \\ Universitat Pompeu Fabra, Barcelona
}

First Draft: August, 1999

This Draft: January, 2000

\begin{abstract}
Some current utility models presume that people are concerned with their relative standing in a reference group. If this is true, do certain types care more about this than others? Using simple binary decisions and self-reported happiness, we investigate both the prevalence of "difference aversion" and whether happiness levels influence the taste for social comparisons. Our decision tasks distinguish between a person's desire to achieving the social optimum, equality or advantageous relative standing. Most people appear to disregard relative payoffs, instead typically making choices resulting in higher social payoffs. While we do not find a strong general correlation between happiness and concern for relative payoffs, we do observe that a willingness to lower another person's payoff below one's own (competitive preferences) seems correlated with unhappiness.
\end{abstract}

Keywords: Happiness, Relative Payoffs, Social Preferences, Subjective Well-being

JEL Classification: A12, A13, B49, C91, D63.

\footnotetext{
* Financial support from the Russell Sage Foundation is gratefully acknowledged. We thank Sonja Lyubomirsky for providing the subjective happiness questionnaire. We also thank Nick Feltovich, Ernan Haruvy, Rosemarie Nagel, Matthew Rabin, and seminar participants at the Russell Sage Foundation Summer Institute in Behavioral Economics for helpful comments and suggestions. Charness gratefully acknowledges support from the MacArthur Foundation. Contact: Gary Charness, Department of Economics, 549 Evans Hall \\# 3880, University of California, Berkeley, CA 94720-3880, Email: charness@econ.berkeley.edu, Brit Grosskopf, Department of Economics, Universitat Pompeu Fabra, Ramon Trias Fargas 25-27, 08005 Barcelona, Spain, Email: grosskop@upf.es
} 
"I'd rather be a big enchanted prince in a small pond than a small enchanted prince in a big pond." -

Frank (1985), (secondary source)

\section{INTRODUCTION}

Subjective states of mind are often not directly observable, but can be quite important in personal interactions and as determinants of economic activity. A large body of laboratory experiments has shown that people do not always choose to maximize their own financial reward, apparently being influenced by non-monetary considerations. There is a growing interest in economics in attempting to explain the motivations for such behavior. Some recent models (Bolton \& Ockenfels, forthcoming; Fehr \& Schmidt (1999); Falk \& Fischbacher (1999)) presume that people are averse to differences in relative payoffs - that is, if their own monetary reward is unaffected, people prefer payoff equality to payoff disparity. However, there is little unconfounded experimental evidence in support of this view.

The presumption is that many people are concerned with social comparisons. Frank (1985) points out that "people's concerns about where they stand on the economic totem pole shape people's behavior in systematic, observable, and often unexpected ways." But what is the source for this posited inclination toward social comparisons? Can we determine which factors affect the degree of one's difference aversion? This is potentially very useful information for determining policy in a number of socioeconomic contexts. One possibility is that a person's level of happiness or subjective well-being 
may influence any tendency to prefer payoff equality. It seems a natural view that if one is "happy," comparisons with other individuals are less compelling. ${ }^{1}$

We conduct an experimental study to investigate the degree to which a concern for relative payoffs is present in the heterogeneous population of individuals. Participants make unilateral choices in dictator game variants where the decision has little or no effect on the chooser's own material payoff, but a substantial effect on a second person's material payoff. This approach limits or removes the influence of own moneymaximization, permitting a cleaner test of the degree of influence of relative payoffs. Our results have immediate implications for models of nonpecuniary behavior in economic settings. We address the question of whether there exists a relationship between a person's (self-reported) happiness and the importance she attaches to relative payoffs. One specific hypothesis is that those who are less happy may seek solace in improving their relative standing in a group.

We feel it is reasonable to expect that the motivational strength of relative payoffs will be greatest for local, rather than global, comparisons. Negative feelings seem much stronger for adverse comparisons with our immediate associates than for adverse comparisons to people who are distant in place or time. Moreover, "fairness" and "equity" (both usually discussed in abstract, philosophical terms) are very closely linked to the concept of local status. In this sense, a laboratory experiment may therefore be a plausible approach for investigating the issue of relative standing.

\footnotetext{
${ }^{1}$ Sociophysiological experiments have demonstrated, for example, that specific measures of autonomic nervous system arousal are strongly influenced by status in social interactions (e.g. Reiser, Reeves \& Armington (1955) and Long, Lynch, Machiran, Thomas \& Malinow, (1982)). Long et al. (1982) found consistently higher heart rate and blood pressure readings among subjects interacting with people who outranked them than among subjects interacting with people of equal rank.
} 
The question arises as to how people conceive of happiness and whether there exists a common meaning. With respect to the measurement of happiness, there is no obvious alternative to self-reported data. Survey evidence has its limitations, of course, and we may wonder whether there is really any relationship between how happy people say they are and how happy they actually feel. ${ }^{2}$ There is a vast literature on the measurement of subjective well-being and psychologists have long been eliciting information by using responses to questionnaires. ${ }^{3}$

The prevailing view in economics has been that one should examine the preferences revealed in observable behavior, since self-reported preferences may be biased by various considerations. However, this methodological philosophy has been challenged (e.g., Sen (1972) and (1986)); perhaps economists should not be too critical of using survey data in this instance, as self-reported data from unemployment and census surveys are typically used for mainstream economic analysis. Since a large body of research has linked self-reported happiness to objective measures of well-being ${ }^{4}$ and since measures of self-reported happiness are also very stable over time (e.g., Wilson (1960)), we have some confidence that self-reported happiness is linked to people's perceived happiness.

\footnotetext{
${ }^{2}$ Woody Allen, who emphasizes his purported unhappiness by saying: "Most of the time I don't have much fun. The rest of the time I don't have any fun at all.", also self-reports earning a considerable amount of money.

${ }^{3}$ See Fordyce (1988) and Konow \& Earley (1999) for excellent literature surveys on the history of investigations using subjective happiness measures. Measurement of subjective well-being has been ongoing in psychology at least since Wilson (1960).

${ }^{4}$ For example, people who say they are not happy are much more likely to exhibit physical symptoms of distress, such as rapid heartbeat, frequency of headaches, digestive disorders, and dizziness (see Bradburn \& Noll, (1969)). Indexes of self-reported happiness are also strongly related to clinical symptoms of depression, irritability, and anxiety (see Bachman, Kahn, Davidson \& Johnston, (1967)), as well as a number of observable behaviors that are commonly taken as symptoms of psychological well being (see Bradburn \& Caplovitz, (1965)). People who consider themselves happy are more likely than others to initiate social contacts with friends.
} 
While economists largely ignored happiness in the two decades following the work of Easterlin (1974), the last few years have seen a growing interest in this topic among economists (e.g., Easterlin (1995); Oswald (1997); Frank (1997)). Studies such as Konow \& Earley (1999) and Frey \& Stutzer (1999) relate economic indicators such as wealth and unemployment to happiness, and use responses to questionnaires to measure subjective well-being. Happiness measures from such surveys have been found to have a strong degree of consistency and validity. For instance, Konow \& Earley (1999) use a variety of measures and find a high degree of correlation among these.

Our results indicate a surprisingly low propensity to prefer lower payoffs for other people: People generally choose to maximize the material payoffs of others, even when these are greater than their own. Two-thirds of participants choose (Other, Self) payoffs of $(900,600)$ over $(600,600)$ and $89 \%$ choose $(600,600)$ over $(400,600){ }^{5}$ When told that they would receive 600 and given an opportunity to select a payoff for a second person from the range of 300 to 1200 , only $10 \%$ of participants chose 600 for the other person, while $74 \%$ chose 1200 . It appears that people are more concerned with the aggregate social payoff or the minimum payoff received by anyone than they are with relative payoffs. This result is more consistent with the Charness \& Rabin (1999) "quasimaximin preferences" than with those models that adopt "difference aversion" as a social motivation.

We did not find support for the hypothesis that happiness levels are generally inversely related to a preoccupation with relative payoffs, perhaps because we find little concern for social standing and so our test has less power. However, we do see a pattern

\footnotetext{
${ }^{5}$ Each unit represents one Spanish peseta, then valued at about 150 to $\$ 1$.
} 
linking a willingness to lower another person's material payoff below one's own with low levels of self-reported happiness. In this sense, perhaps misery does love company.

The remainder of this paper is organized as follows: Section 2 presents the background to the issues in question, as well as relevant previous evidence. In Section 3, we describe our experimental design and happiness questionnaires. Results are given in Section 4 and Section 5 concludes.

\section{BACKGROUND AND PREVIOUS EVIDENCE}

Do most people care about relative payoffs? In a certain sense, this depends on the environment and the consequences ensuing from the disparity. In the field, considerable differences in wealth can lead to very different consumption possibilities. A laboratory experiment cannot realistically provide such disparities, so the applicability of results could be called to question to the extent that large (and proximate) differences are representative. But it is now common to test theoretical models with laboratory data and indeed some models are derived from an analysis of such data.

It may also be difficult to isolate social preferences in life situations, as other motivations (such as reciprocity preferences) may be present. For example, one relevant economic application is the question of why wage rates among co-workers are so much more egalitarian than predicted by standard economic theories of the labor market. Fairwage and gift-exchange models (e.g., Akerlof (1982); Akerlof \& Yellen (1990)) suggest 
that worker effort and firm productivity are dependent on employee's perception of fair treatment.

One manifestation is that many people are averse to large disparities in wages, regardless of the absolute level of one's wage. If employees were happier, perhaps they would be less concerned with these differences. Yet here the underlying issue seems to be displeasure from a deliberate choice by an employer rather than an objection to the allocations per se. In general, one may not mind that someone else has more, unless there is dissatisfaction with the allocation process.

In fact, this problem of confounded explanations also applies to most experimental games. The classic experimental illustration of nonpecuniary behavior is the rejection of a positive offer of money in the ultimatum game. ${ }^{6}$ Many variants have evolved, including versions with highly-restricted proposer choice sets, nonzero rejection payoffs, and multiple players in various combinations. While this game is quite successful at eliciting monetary sacrifice, it was not designed to identify the motivation behind this choice. Specifically, it is unclear here whether rejections are induced by a dislike for unequal payoffs or by feelings of negative reciprocity.

Some current theories of non-pecuniary utility are based on the premise that subjects who sacrifice money do so because they dislike unequal payoffs. Specifically, Bolton \& Ockenfels (forthcoming) and Fehr \& Schmidt (1999) offer utility formulations, which state that unequal payoffs reduce one's utility and that this effect grows with greater disparity in material payoffs. Thus, if monetary reward is held constant, people

\footnotetext{
${ }^{6}$ Presented in Güth, Schmittberger \& Schwarze (1982). A mutually-anonymous pair is provisionally given a sum of money. One person is selected to propose a division of this sum. The other person then can
} 
should prefer payoffs to be identical. A central feature of our experimental design is to limit the range of payoffs for the chooser, but allow the payoffs for a second person (who has had no say in the process) to vary considerably. We are unaware of previous experimental research using games with this feature, although Charness \& Rabin (1999) borrowed this design feature from our study.

The work closest to ours is in the field of social psychology: Lyubomirsky \& Ross (1997) tested the hypothesis that self-rated unhappy people would be more sensitive to social comparisons than would happy ones. They find that low self-esteem seems to be associated with the tendency for people to compare themselves with the less fortunate ones. Moreover, happy people are less sensitive to unsolicited social comparison information in general, and less vulnerable to unfavorable social comparisons information in particular, than unhappy people.

However, rather than observing participants' choices over various monetary allocations, they tested the effect of 1) an experimental confederate's performance in solving anagrams, and 2) differences in feedback on their own teaching performance, on the moods and the self-evaluations of the participants. Their studies are complex in execution; our design employs similar self-rated happiness measures (in Study 2 it is identical to theirs), but we use very simple games (with monetary payoffs) to elicit preferences. The question remains whether this happiness-dependent inclination for social comparisons has a significant influence on actual choices that determine advantageous relative outcomes.

accept the proposal, in which case the money is divided as proposed, or reject the proposal, in which case both receive nothing. 
The necessity to link financial incentives to inferences about human behavior has long been a sharp theoretical dividing line between economics and social sciences such as psychology. Camerer \& Hogarth (1999) find that the effect of incentives on human behavior is mixed and complicated. ${ }^{7}$ Economists presume that little or no effort will be made without the promise of monetary reward, so that the accuracy of such choices is of dubious quality.

While some economists may be skeptical of self-reported data, the idea that would agree that subjective well-being can influence economic behavior seems less controversial. For example, Bewley (1998) interviewed over 300 business people and consultants, labor leaders, and counselors of unemployed people (all in the Northeast of the United States) in order to find out why, during the recession of the early 1990's, wages and salaries declined at only a few firms. He found that employers were reluctant to cut pay because they believed doing so would hurt employee morale, leading to lower productivity and current or future difficulties with hiring and retention. It was thought that these effects would in the end cost more than the savings from lower pay.

There have been studies on whether "money buys happiness." The relativist position (e.g., Easterlin (1973) and (1974)) is that happiness is based on a comparison to others. On the other hand, Veenhoven (1993) suggests that greater wealth only matters for people's happiness when their basic needs are not being met. Konow \& Earley (1999) examine the relationship between material generosity, as captured by dictator experiment allocations, and self-reported happiness. Their results, derived from students in Los

\footnotetext{
${ }^{7}$ There are some tasks in which the presence and amount of financial incentives reliably improve average performance (e.g., problem-solving or judgment tasks). In other tasks incentives don't matter, presumably
} 
Angeles, indicate that higher wealth is not correlated with higher subjective well-being. However, they find that more generous individuals (those allocating positive amounts in the dictator game) are happier. The high Spearman coefficients for the pairwise correlation of their 15 separate indices of subjective well-being provide strong evidence for the consistency of these measures.

Frey \& Stutzer (1999) attempt to estimate the determinants of individual happiness and find that the critical economic problem of preference measurement can be eased by relying on self-reported happiness as well as observed behavior. While unemployed people are clearly unhappier than employed people, there is little difference in life satisfaction across income classes in Switzerland. Interestingly, their analysis suggests an immediate implication, as they find that citizens seem to have higher subjective well-being when there are more possibilities for participating in the democratic process.

Overall, any linkage between wealth and happiness is unclear. We can observe people's preferences in simple experimental decisions and we also have some reason to believe that self-reported happiness data are meaningful. The Lyubomirsky \& Ross (1997) results suggest that there is a difference in sensitivity to social comparisons across levels of happiness, so that if there is much concern for relative payoffs, we might expect some correlation between self-reported happiness and observed choice. 


\section{METHODOLOGY}

\subsection{Study 1}

The Experiment: One hundred and twenty-one people participated in this experiment. Each of the 4 sessions took about one hour; no participant attended more than one session. Subjects were recruited by campus advertisements offering monetary reward for participating in a decision task. All participants were undergraduate students at the Universitat Pompeu Fabra in Barcelona, majoring in either economics, business or humanities. Average earnings (in Spanish pesetas, then about 150 to $\$ 1$ ), were around $\$ 9$ for a 45 minute session, this included a small show up fee of 200 pesetas. Participants were paid individually and privately at the end of the experimental session. A full description of the instructions and record sheets issued to the subjects can be found in Appendix A. ${ }^{8}$

All participants initially met in one large room. After a brief introduction, roles were assigned by each participant's random draw of a number from an opaque box. Half of the participants (type "A" subjects) stayed in the room whereas the other half (type "B" subjects) moved to another one. Having all participants meet in one room at the outset was important to make it credible that another real person's payoff was dependent on a player's decision. Pairings were random and anonymous. Subjects were given written

the task is too hard or has a flat payoff frontier. Monetary incentives may even be counterproductive.

${ }^{8}$ Some effort was made to account for subject pool variability across the time of day and the day of the week by conducting sessions at different times of day and at different times during the week. No significant differences were found. 
instructions concerning rules and payoffs of the game, these instructions were read aloud by the experimenter, and subjects were told their roles (either A or B). ${ }^{9}$

Each person was confronted with two separate decisions, presented one at a time. $^{10}$
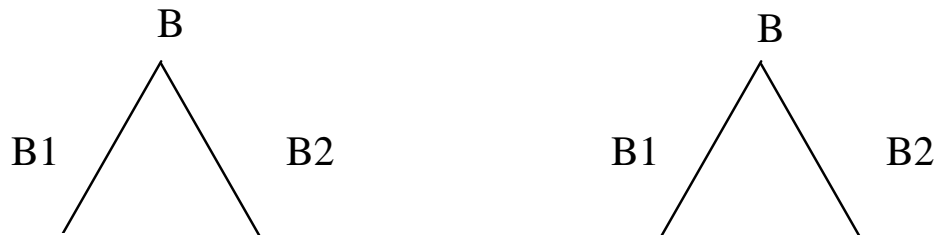
(A) 900
$600 \quad(\mathrm{~A})$
(A) 400
600
(A)
(B) 600
600
(B)
(B) 600
600
(B)

Participants knew that only one outcome reached would be used to determine material payoffs. Subjects who were randomly assigned the role "A" (who had no say in the decision process) were asked what they would do if they were in the B role; moreover, in 3 of the 4 sessions, they were asked to predict type "B" players' choices. The choice to be used for payment purposes was selected by a public coin toss. ${ }^{11}$

The Happiness Questionnaire: After completing all decision tasks, subjects were asked to evaluate their level of happiness by responding to a questionnaire on subjective

\footnotetext{
${ }^{9}$ Subjects in both rooms were also told the content of the instructions of the other group.

${ }^{10} \mathrm{We}$ alternated (by session) the order in which the decisions were presented, finding that $72.7 \%$ chose $(900,600)$ when this was in the first decision and $57.1 \%$ chose it when this was in the second decision. The test of proportions (Glasnapp \& Poggio (1985)) for effects from the order of decisions gives $Z=1.28, p=$ .20 , two-tailed. Potential correlations between choices and happiness levels might be weakened by order effects.

${ }^{11}$ Students were asked whether they'd prefer a single die roll for the whole group to select the payoffdetermining decision of player B or whether they'd prefer to have individual rolls. They unanimously preferred the single die roll for the whole group. One explanation for this might be the fact that people do not mind a bad outcome too much if it affects all at the same magnitude, but being the only one who is affected with an unfavorable outcome is unbearable.
} 
happiness ${ }^{12}$ and choosing one of 11 gradations of happiness (ranging from "Extremely happy" to "Extremely unhappy". Full details of the questionnaire are provided in Appendix A. One question addressed the general level of happiness, while a second question asked subjects to estimate their immediate (or momentary) level of happiness. ${ }^{13}$ We also asked people to estimate the percentage of time they felt happy, neutral, or unhappy. Our happiness measures are derived from a combination of the scale responses and these percentages. To check for internal consistency, we included questions about the happiness of an "average" person, the happiness of the respondent in comparison to this person, and whether the respondent recalled anything that happened to make them happy or unhappy that day.

\subsection{Study 2}

The Experiment: A total of 108 subjects participated in this experiment. The subject pool, recruiting method, and average payments were very similar to that in Study 1. A full description of the instructions and record sheets issued to the subjects can be found in Appendix B. All participants initially met in one large room and were given identical instructions. After a brief introduction, subjects drew identification numbers from an opaque box and then half of the participants (odd numbers) moved to another room.

In this study, subjects were first asked to complete a happiness questionnaire. Three decision tasks followed, again with "A" and "B" roles.

\footnotetext{
${ }^{12}$ This subjective well-being questionnaire was adapted from that in Fordyce (1988).
} 


\section{Decision 1}

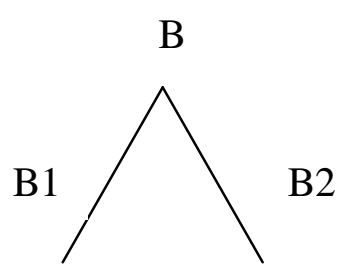

Decision 2

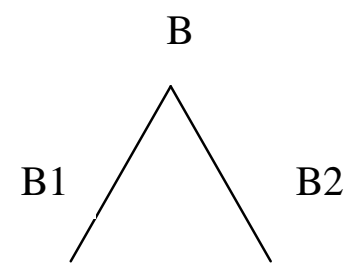
$\begin{array}{llll}\text { A } & 1200 & 600 & \text { A } \\ \text { B } & 625 & 600 & \text { B }\end{array}$
A 625
1200 A
B 625
600 B

\section{Decision 3}

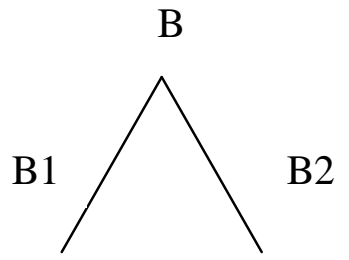
A 600
x $\quad$ A $\quad 300 \leq x \leq 1200$
B 600
600 B

Subjects in each room were presented with these decisions one at a time. ${ }^{14}$ Participants in both rooms were asked to make decisions contingent upon the assumption that they were in the B role. They were told that their actual role (for payment purposes) in the decision would be determined at the end of the session and that only one decision by a group in one of the two rooms would be chosen (using a six-sided die) to determine monetary consequences. Pairings were anonymous and determined by the numbers drawn by the participants. All participants viewed the outcome of the die roll at the end of the session.

\footnotetext{
${ }^{13}$ While we had no specific hypothesis concerning these two measures it seemed interesting to look for any regular pattern across them.
} 
The Questionnaire. We used the format of Lyubomirsky \& Ross (1997). Participants were given four questions (shown in full in Appendix B) about their state of happiness. These inquired about one's general happiness and solicited comparisons to others. The question and response format was a seven-point Likert scale; i.e., a scale identifying agreement or disagreement with a statement in degrees ranging from "strongly disagree" to "strongly agree".

After all decision sheets had been collected, subjects were given a list of words containing 12 positive effect and 12 negative effect attributes. They had three minutes to memorize them. After the list was collected by the instructor, subjects were asked to write down 10 (and only 10) of them on a separate sheet of paper. ${ }^{15}$ It was amazing to see the amount of effort and passion subjects put into the fulfillment of this request. ${ }^{16}$ This observation might relax the critique toward the necessity for monetary incentives in all cases.

\section{RESULTS}

\footnotetext{
${ }^{14}$ We did not alternate the order in which decision tasks were posted.

${ }^{15}$ This number is constrained because we did not wish to place too much emphasis on memory capabilities per se, but rather on the type of words that subjects remembered most easily.

${ }^{16}$ We refer to our physical perceptions of how participants applied themselves to this non-paying task. In a more quantifiable sense, $88.9 \%$ (97) of the subjects listed 10 words, while the other $11.1 \%$ (11) listed either 8 or 9 words.
} 


\section{Study 1}

The Experiment. Table 1 shows the choices in decisions 1 and 2, for both people in the B role ("Live") and people in the A role who made hypothetical decisions as if they were in the B role ("Dead"). In 3 out of 4 sessions (44 out of 60), Dead participants were also asked to estimate the other players' choices.

Table 1 - Study 1 Decisions

\begin{tabular}{|c|c|c|c|c|}
\hline \multirow{2}{*}{ Group } & \multicolumn{2}{|c|}{$\begin{array}{c}\text { Decision 1 } \\
(900,600)\end{array}$} & \multicolumn{2}{c|}{$\begin{array}{c}\text { Decision } 2 \\
(400,600)\end{array}$} \\
& \multicolumn{2}{|c|}{ vs. $(600,600)$} \\
\hline Live $(\mathrm{N}=61)$ & $65.6 \%(40)$ & $34.4 \%(21)$ & $11.5 \%(7)$ & $88.5 \%(54)$ \\
\hline Dead1 $(\mathrm{N}=60)$ & $73.3 \%(44)$ & $26.7 \%(16)$ & $8.3 \%(5)$ & $91.7 \%(55)$ \\
\hline Dead2 $(\mathrm{N}=44)^{17}$ & $63.6 \%(28)$ & $36.4 \%(16)$ & $11.4 \%(5)$ & $88.6 \%(39)$ \\
\hline
\end{tabular}

We were a bit surprised at how few people chose $(600,600)$ over $(900,600)$, as would be predicted by models of inequality aversion. The percentage of people choosing $(400,600)$ is in line with the proportion of people classified as having competitive preferences in the "ring test" of social-value orientations. ${ }^{18}$ Interestingly, subjects who are asked to estimate the choice of the other players behave significantly differently than subjects not assigned this task. Note that the hypothetical choice rates for A's who also estimated B choices were nearly identical to actual B choice rates.

We can also check how the predictions of the Dead group subjects compare with their own hypothetical choices in the decisions:

Table 2 - Hypothetical Decisions and Predictions Average \% Predicted for

\footnotetext{
${ }^{17}$ Hypothetical choices of the Dead group for the three sessions in which subjects were asked to estimate the other group's behavior.

${ }^{18}$ See Liebrand (1984), McClintock \& Liebrand (1988), and Offerman, Sonnemans, \& Schram (1996).
} 


\begin{tabular}{|c|c|}
\hline Dead Group Choices $(\mathrm{N}=44)$ & $(900,600)$ \\
\hline Chose $(900,600)$ in Decision 1 $(\mathrm{N}=28)$ & 69.1 \\
\hline Chose $(600,600)$ in Decision 1 $(\mathrm{N}=16)$ & 29.2 \\
\hline & $\begin{array}{c}\text { Average \% Predicted for } \\
(400,600)\end{array}$ \\
\hline Chose $(400,600)$ in Decision 2 $(\mathrm{N}=5)$ & 68.8 \\
\hline Chose $(600,600)$ in Decision 2 $(\mathrm{N}=39)$ & 19.4 \\
\hline
\end{tabular}

Not surprisingly, subjects make estimates that reflect a false consensus. ${ }^{19}$ According to the definition used by Mullen et al. (1985), the false consensus hypothesis (see also Ross et al. (1977)) says that people who engage in a given behavior will estimate that behavior to be more common than the estimate made by people who engage in alternative behaviors. ${ }^{20}$ While we don't know if people believe their own predictions, this hypothesis is strongly supported by our data. The difference in estimates across groups is highly significant $(p<.01$, Fisher Exact Test) for both Decisions 1 and 2.

Note that the overall predictions of subjects who made the hypothetical choice to maximize the other person's payoff were far more accurate than the predictions of those who chose not to do so. While people in general are clearly prone to think that others will act in the same manner as themselves, the predictions of the social maximizers are accurate, unlike the predictions of people who would choose the lower payoff for the other person. Perhaps the latter group is ex post attempting to justify their own behavior by stating (and perhaps inducing themselves to believe) that they think others would have acted similarly.

\footnotetext{
${ }^{19}$ Ross et al. (1977) first used the term "false consensus effect". It has been observed in several experiments conducted by economists, although these were not designed to test for this effect (see for example Selten \& Ockenfels (1998) and Jacobsen \& Sadrieh (1996)).

${ }^{20}$ Engelmann \& Strobel (1999) point out that a (truly) false consensus effect is considered to be present if people, when forming expectations concerning other people's decisions, weight their own decision more heavily than that of a randomly selected person from the same population.
} 
The Happiness Questionnaire. Figures 1 to 4 show the distribution of responses to the subjective happiness questionnaire for the Live and Dead subjects, respectively. General happiness of the Live group has a spike at eight, whereas the distribution of momentary happiness is smoother, with a mode of seven. ${ }^{21}$ The distribution is similar for the Dead group, although both, general and momentary happiness, have their mode at 8 . Summary statistics are given in Table 3.

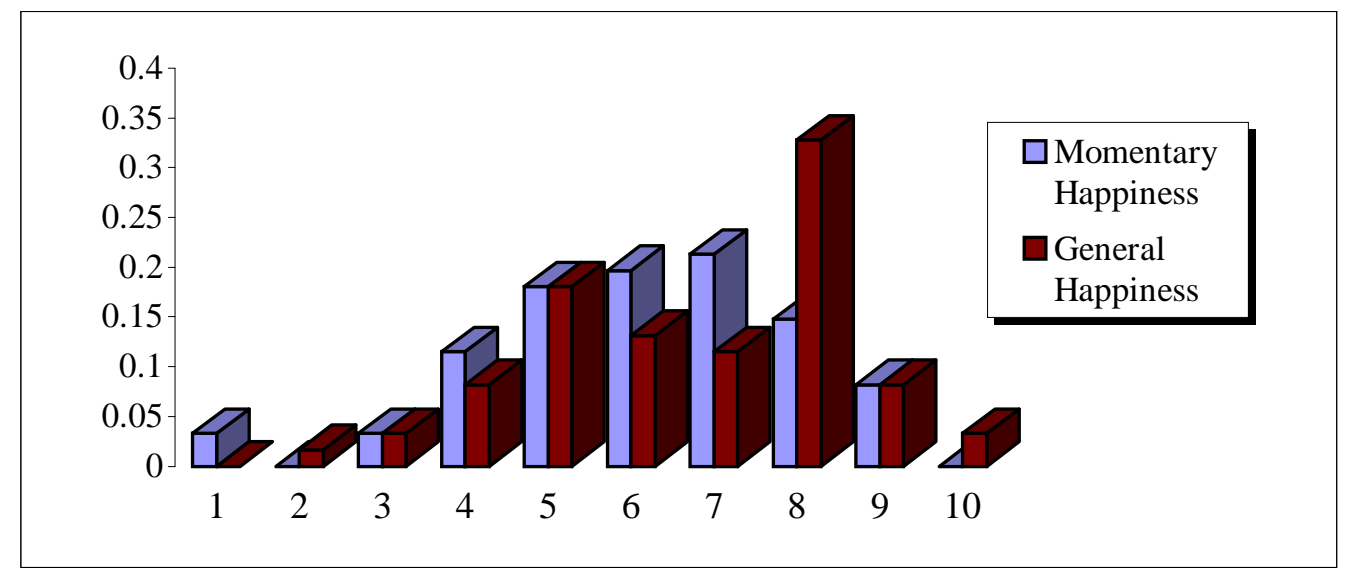

FIGURE 1: Histogram of responses to the happiness questionnaire (Live group) (Possible responses were from $0=$ "Extremely unhappy" to $10=$ "Extremely happy.")

\footnotetext{
${ }^{21}$ We ran one pilot experimental session with first year graduate students. The average response to the general happiness is not much different from the undergraduate responses (mean=6.62, median=7), but the response to the momentary happiness is drastically less positive (mean=4.76, median $=5)$ ). Even though grad school may not change one's view of one's general happiness but it seems to result in lower perceived momentary happiness.
} 


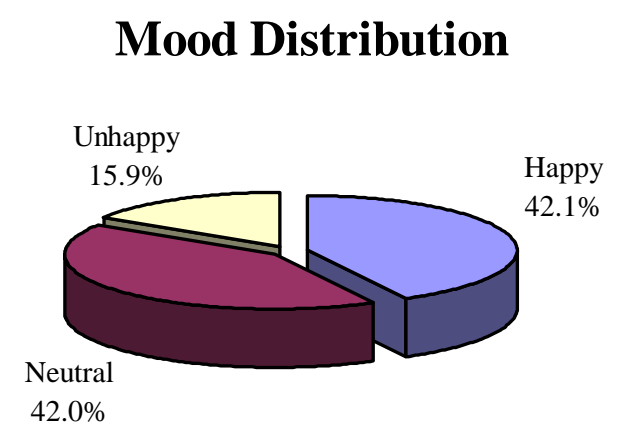

FIGURE 2: Average percentages of time spent in a happy, unhappy or neutral mood (Live group)

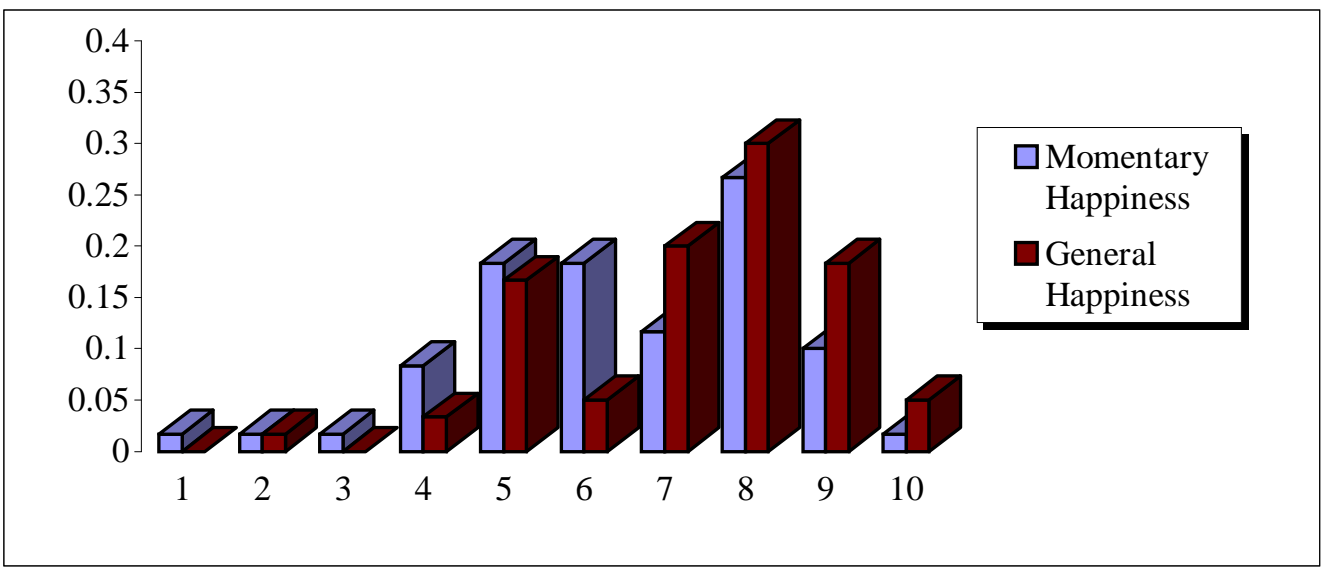

FIGURE 3: Histogram of responses to the happiness questionnaire (Dead group) (Possible responses were from $0=$ "Extremely unhappy" to $10=$ "Extremely happy".) 


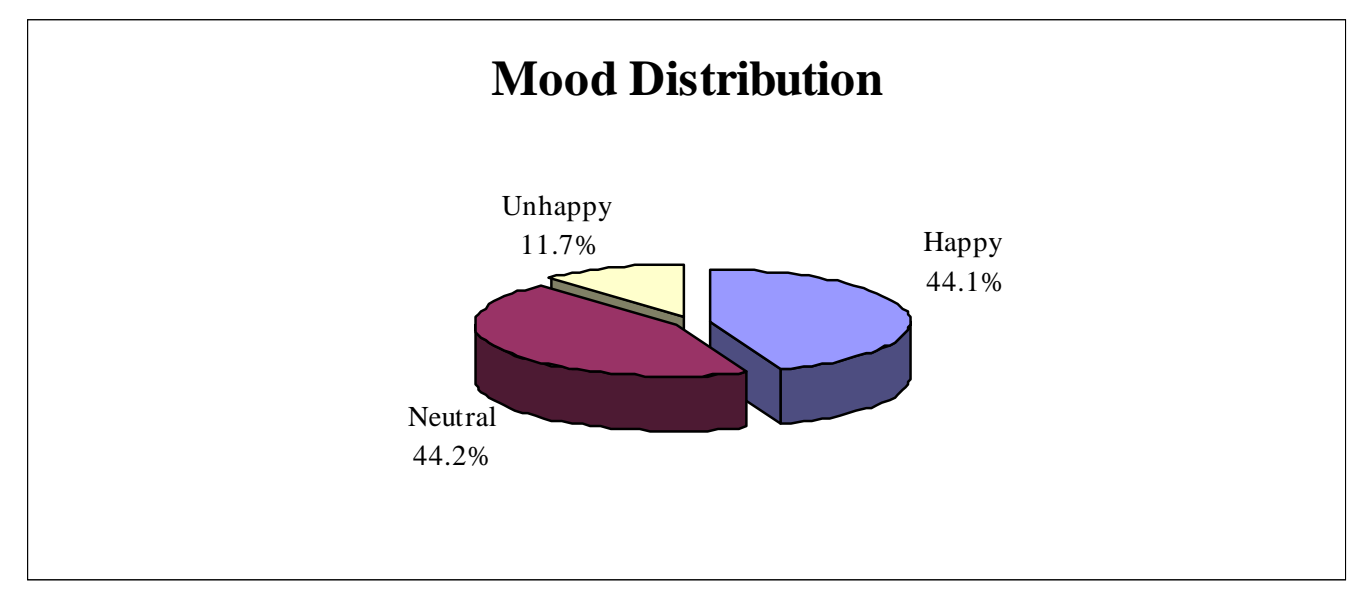

FIGURE 4: Average percentage of time spent in a happy, unhappy or neutral mood (Dead group)

Table 3 - Mean Values of Self-reported Happiness

\begin{tabular}{|c|c|c|c|c|c|}
\hline Group & \multicolumn{2}{|c|}{ Happiness } & \multicolumn{3}{c|}{ \% of time } \\
\hline & General & Momentary & Happy & Neutral & Unhappy \\
\hline $\begin{array}{c}\text { Live } \\
(\mathrm{N}=61)\end{array}$ & 6.64 & 6.07 & 42.1 & 42.0 & 15.9 \\
\hline $\begin{array}{c}\text { Dead } \\
(\mathrm{N}=60)\end{array}$ & 7.25 & 6.45 & 44.1 & 44.2 & 11.7 \\
\hline
\end{tabular}

The nonparametric Wilcoxon matched pairs signed-ranks test finds a significant difference between general happiness and momentary happiness, for both the Live group $(Z=-2.59, p=.01$, two-tailed $)$ and the Dead $\operatorname{group}(Z=-3.67, p<.001$, two-tailed $){ }^{22}$

Subjects consistently seemed to believe that they are generally happier than currently. Figure 5 coplots the cumulative distribution of momentary happiness and general happiness for all subjects. Momentary happiness first order stochastically dominates general happiness.

\footnotetext{
${ }^{22}$ See Siegel \& Castellan (1988) for descriptions of the nonparametric tests used in this paper.
} 


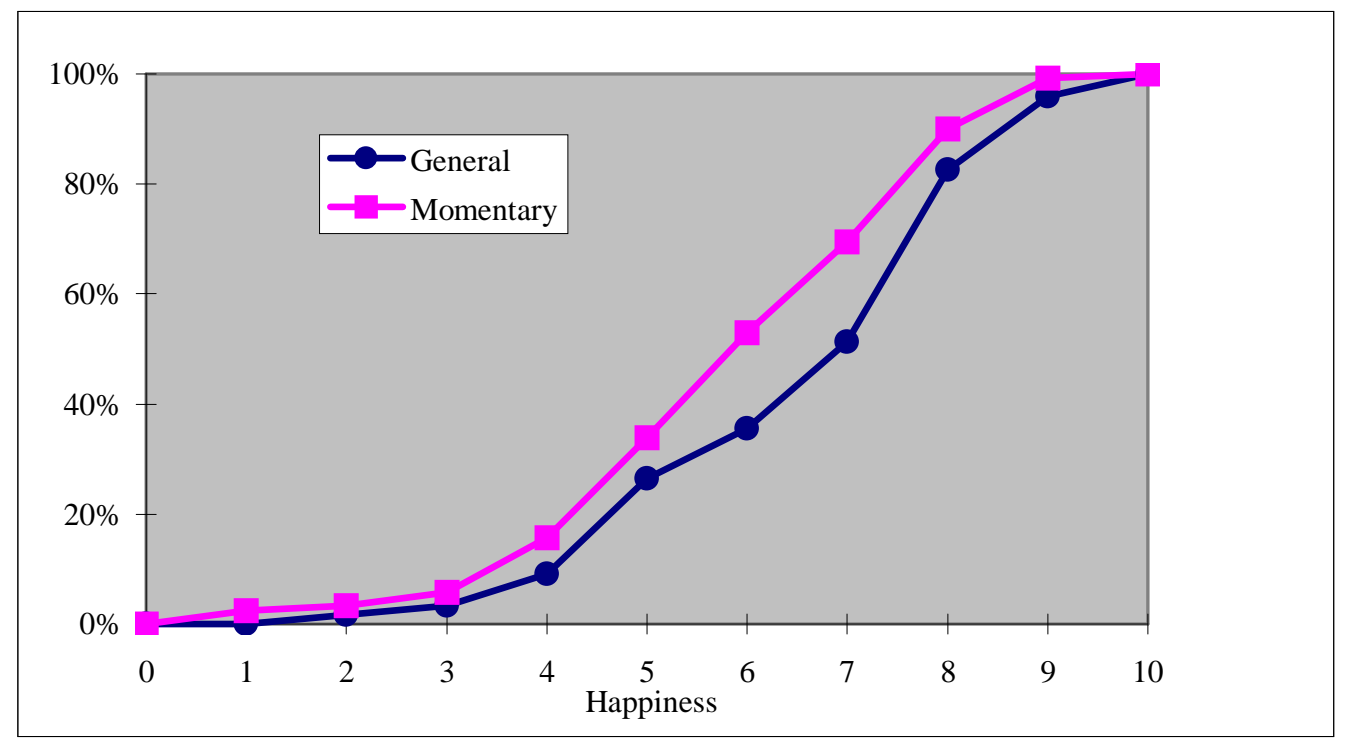

FIGURE 5: Cumulative distribution of general and momentary happiness (Live and Dead aggregated)

The robust rank-order test indicates a modest degree of significance for differences in happiness levels across Live and Dead groups (for general happiness, $\grave{U}=$ 1.86, $p=.06$, two-tailed; for momentary happiness, $\grave{U}=1.16, p=.24$, two-tailed). There is very little difference between these groups in terms of the percentage of time spent in each happiness category. ${ }^{23}$

Happiness researchers face a bewildering multitude of measurement possibilities; numerous scales have been developed over the years. ${ }^{24}$ While one could derive a multitude of measures from the reported data, here we limit ourselves to a measure adapted from the one used in Fordyce (1988). This is given by the following equation:

\footnotetext{
${ }^{23}$ The robust rank-order test (Live goup data vs. Dead group data) gives for \%happy $\grave{U}=.1, p=.92$, twotailed; \%neutral $\grave{U}=.76, p=.45$, two-tailed; \%unhappy $\grave{U}=-1.29, p=.2$, two-tailed.
} 


$$
H M=\frac{\text { ScaleScore } * 10+0.5 *(\% \text { happy }-\% \text { unhappy })+50}{2}
$$

ScaleScore is the numerical equivalent $(0-10)$ of the 11 -gradation scale. ${ }^{25}$

Table 4 shows the average happiness measures for subjects (Live group) making the indicated choices:

Table 4 - Happiness Measures by Decision

\begin{tabular}{|l|c|c|c|c|}
\hline & \multicolumn{2}{|c|}{ Decision 1 } & \multicolumn{2}{c|}{ Decision 2 } \\
\hline & $\mathbf{9 0 0 / 6 0 0}$ & $\mathbf{6 0 0 / 6 0 0}$ & $\mathbf{4 0 0 / 6 0 0}$ & $\mathbf{6 0 0 / 6 0 0}$ \\
\hline HM1 (general happiness) & 63.9 & 66.3 & 58.2 & 65.6 \\
\hline HM2 (momentary happiness) & 60.8 & 63.9 & 56.0 & 62.6 \\
\hline
\end{tabular}

Correlations. We observe small differences between average happiness levels for Decision 1 and moderate differences in Decision 2. The nonparametric Median test finds virtually no difference in happiness measures for Decision $1\left(\chi^{2}(1)=.00, p=.95\right.$, twotailed for $H M 1$ and $\chi^{2}(1)=.37, p=.2$, for $\left.H M 2\right)$. The differences for Decision 2 are

\footnotetext{
${ }^{24}$ Konow \& Earley (1999) give an excellent survey of the different measures developed over the years. See also Fordyce (1988).

${ }^{25}$ The measure used in Fordyce (1988) was $H M=\left(\right.$ ScaleScore $^{*} 10+\%$ happy $) / 2$. We feel that it is also useful to differentiate between time spent in neutral or unhappy states, so we modified the measure accordingly. It is easy to see that both measures range from 0 to 100 and that a neutral person receives a happiness rating of 50 .
} 
modest $\left(\chi^{2}(1)=1.78, p=.2\right.$, two-tailed for $H M 1$ and $\chi^{2}(1)=1.52, p=.2$, two-tailed for HM2), but do suggest a trend. ${ }^{26}$

In order to further test for significance, we also calculate Spearman correlation coefficients.

Table 5 - Spearman Correlations - Happiness Measures and Decisions (Live)

\begin{tabular}{|c|c|c|c|c|c|c|}
\hline & Gen. & Mom. & $H M 1$ & $H M 2$ & Decision 1 & Decision 2 \\
\hline General & - & $\begin{array}{c}.666^{* *} \\
(.000)\end{array}$ & $\begin{array}{c}.938^{* *} \\
(.000)\end{array}$ & $\begin{array}{c}.766^{* *} \\
(.000)\end{array}$ & $\begin{array}{c}.044 \\
(.736)\end{array}$ & $\begin{array}{c}-.129 \\
(.323)\end{array}$ \\
\hline Momentary & & - & $\begin{array}{c}0.702^{* *} \\
(.000)\end{array}$ & $\begin{array}{c}.926^{* *} \\
(.000)\end{array}$ & $\begin{array}{c}.108 \\
(.406)\end{array}$ & $\begin{array}{c}-.156 \\
(.231)\end{array}$ \\
\hline$H M 1$ & & & - & $\begin{array}{c}.871^{* *} \\
(.000)\end{array}$ & $\begin{array}{c}.101 \\
(.437)\end{array}$ & $\begin{array}{c}-.127 \\
(.329)\end{array}$ \\
\hline HM2 & & & & - & $\begin{array}{c}.138 \\
(.288)\end{array}$ & $\begin{array}{c}-.151 \\
(.247)\end{array}$ \\
\hline Decision 1 & & & & & - & $\begin{array}{c}.172 \\
(.185)\end{array}$ \\
\hline Decision 2 & & & & & & - \\
\hline
\end{tabular}

Note: $p$-values are given in parenthesis (** indicates significance on a level of .01 (one-tailed), and * denotes a significance level of .10 (one-tailed))

This table clearly illustrates that the happiness measures are well correlated. ${ }^{27}$ There is a modest positive correlation for both measures and choices in Decision 1 , as well as a modest negative correlation for these measures and choices in Decision 2. In no case were these correlations statistically significant at conventional levels, although all coefficients have the anticipated sign.

\footnotetext{
${ }^{26}$ In terms of statistical significance, the $p$-values are about .2 for these comparisons. However, $\chi^{2}$-test is implicitly a two-tailed test. Given our directional hypothesis, the equivalent one-tailed $p$-value would be around .1.

${ }^{27}$ In fact, Cronbach's alpha (a test for internal consistency) for the metrics of general happiness, momentary happiness, perceived happiness of an average person, and happiness compared to this average person is 0.68 , indicating good consistency across the 4 measures.
} 


\section{Study 2}

The Experiment. The choices in Decisions 1, 2, and 3 are shown below:

Table 6 - Study 2 Decisions $(\mathrm{N}=108)$

\begin{tabular}{|c|c|c|c|c|c|c|c|}
\hline \multicolumn{2}{|c|}{$\begin{array}{c}\text { Decision 1 } \\
(625,625) \text { vs. } \\
(1200,600)^{28}\end{array}$} & \multicolumn{2}{|c|}{$\begin{array}{c}\text { Decision 2 } \\
(1200,625) \text { vs. } \\
(600,600)\end{array}$} & \multicolumn{4}{c|}{ Decision 3 } \\
\hline \multicolumn{2}{|c|}{} & & & $\mathrm{x}<600$ & $\mathrm{x}=600$ & $600<\mathrm{x}<1200$ & $\mathrm{x}=1200$ \\
\hline $33.3 \%$ & $66.7 \%$ & $88.0 \%$ & $12.0 \%$ & $8.3 \%$ & $10.2 \%$ & $7.4 \%$ & $74.1 \%$ \\
$(36)$ & $(72)$ & $(95)$ & $(13)$ & $(9)$ & $(11)$ & $(8)$ & $(80)$ \\
\hline
\end{tabular}

There are some immediate patterns that can be seen. For example, the proportion of people choosing equal payoffs is significantly higher in Decision 1 than in Decision 2 $\left(\chi^{2}(1)=13.96, p<.001\right)$, so that people are clearly influenced by whether equality costs or saves money. We were quite surprised at how few people chose equality in Decision 3 (there are still only 16 of 108 choices for equality, even if we include all choices of $x$ no more than 100 different from 600). There is also very little difference aversion in the data for Decisions 1 and 2: Two-thirds of all participants sacrifice money to yield major inequality in Decision 1, while very few people were willing to sacrifice 25 pesetas to achieve equal payoffs.

If we examine choices across individuals for the three decisions, we find that 62 people always chose the social maximum, while 17 others always chose the social maximum, except where doing so diminished their material payoffs. Only 5 people always chose equality; 3 people always chose the highest relative payoff.

\footnotetext{
${ }^{28}$ The first (second) column below refers to the first (second) option $(625,625)((1200,600))$ respectively. ${ }^{29}$ The full distribution of choices for $x$ was: 300 (4), 301 (1), 500 (2), 560 (1), 599 (1), 600 (11), 700 (1), 800 (2), 900 (2), 1000 (1), 1100 (2), and 1200 (80), where the number in parentheses is the number of times the indicated value of $x$ was chosen.
} 
The Happiness Questionnaire. Following Lyubomirsky \& Ross (1997), we aggregate the responses from the four questions about happiness (happiness in general, compared to friends, compared to happy people, and compared to unhappy people) to form a composite happiness scale. Cronbach's alpha over these four measurements is 0.77 , showing strong internal consistency (this compares to 0.81 in Lyubomirsky \& Ross, 1997). The distribution of the aggregate (or composite) happiness measure is shown below. The mean level is 4.62 and the median is 4.75 .

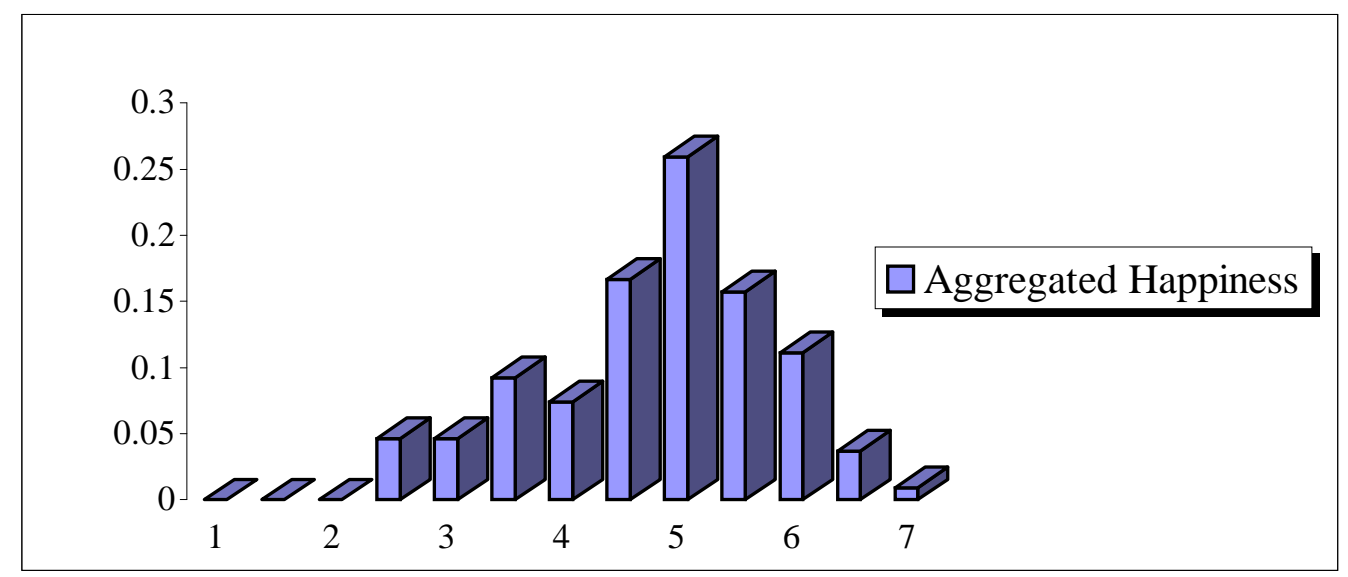

FIGURE 6: Histogram of aggregated happiness

Table 7 reports Spearman correlation coefficients between the happiness measures and the decision choices (a more comprehensive correlation table, which includes responses to other questionnaire items is presented in Appendix C). 
Table 7 - Spearman Correlations - Happiness Measures and Decisions (Study 2)

\begin{tabular}{|c|c|c|c|c|c|c|}
\hline & Gen. & Aggreg. & $\begin{array}{c}\text { Decision } \\
1\end{array}$ & $\begin{array}{c}\text { Decision } \\
2\end{array}$ & $\begin{array}{c}\text { Decision } 3 \\
\text { (a) }{ }^{30}\end{array}$ & $\begin{array}{c}\text { Decision } 3 \\
\text { (b) }\end{array}$ \\
\hline General & - & $\begin{array}{l}.823 * * \\
(.000)\end{array}$ & $\begin{array}{c}.063 \\
(.259)\end{array}$ & $\begin{array}{l}-.014 \\
(.443)\end{array}$ & $\begin{array}{l}-.036 \\
(.357)\end{array}$ & $\begin{array}{l}-.054 \\
(.288)\end{array}$ \\
\hline Aggregated & & - & $\begin{array}{l}.079 \\
(.210)\end{array}$ & $\begin{array}{l}-.029 \\
(.382)\end{array}$ & $\begin{array}{l}-.078 \\
(.212)\end{array}$ & $\begin{array}{l}-.114 \\
(.119)\end{array}$ \\
\hline Decision 1 & & & - & $\begin{array}{l}.463 * * \\
(.000)\end{array}$ & $\begin{array}{l}.270 * * \\
(.002)\end{array}$ & $\begin{array}{c}.071 \\
(.232) \\
\end{array}$ \\
\hline Decision 2 & & & & - & $\begin{array}{l}.483 * * \\
(.000)\end{array}$ & $\begin{array}{l}.197 * \\
(.020)\end{array}$ \\
\hline $\begin{array}{c}\text { Decision } 3 \\
\text { (a) }\end{array}$ & & & & & - & $\begin{array}{c}.632 * * \\
(.000)\end{array}$ \\
\hline $\begin{array}{l}\text { Decision } 3 \\
\text { (b) }\end{array}$ & & & & & & - \\
\hline
\end{tabular}

Note: $p$-values are given in parenthesis (** indicates significance on a level of .01 (one-tailed), and * denotes a significance level of .10 (one-tailed))

As mentioned above, we also asked people to recall 10 of the 24 words shown to them near the end of the session. The average number of "positive" words recalled was 6.11, while the average number of "negative" words recalled was 3.73 . Overall, we find amazing consistancy. The number of positive words recalled is well-correlated with the aggregated happiness level (Spearman coefficient 0.191, $p=.02$, one-tailed), and the number of negative words is negatively correlated with the aggregated happiness (Spearman correlation coefficient $-0.174, p=.04$, one-tailed).

Correlations. We do not find much correlation between our happiness measure and the choices made in Decisions 1 and 2. It would appear that people's preference for higher payoffs muddies the waters, making correlations problematic. A robust rank-order test

\footnotetext{
${ }^{30}$ For the purpose of analysis, in "Decision 3 (a)" a subject is placed in one category if she selects $x>600$ and the other if she selects $x \leq 600$; in "Decision 3(b)" one category has $x<600$ and the other has $x \geq 600$.
} 
gives $\grave{U}=-0.83(p=.40$, two-tailed) for Decision 1 (the opposite direction from the prediction of the hypothesis) and $\grave{U}=0.32(p=.76$, two-tailed) in Decision 2 . In any event, we do not find that the willingness to sacrifice money correlates with subjective well-being, perhaps in contrast to the Konow \& Earley (1999) conclusion that happy people are more generous.

However, in Decision 3 we find that the desire to assign a lower payoff than one's own to the other person is related to one's happiness level. If we group subjects by whether or not their choice of $x$ was less than 600 , we find that the mean happiness level for those who select $x<600$ is 4.25 and 4.66 for other people. The robust rank-order test statistic is $\grave{U}=1.07$ ( $p=.14$, one-tailed) and the Spearman correlation coefficient is $0.114(p=.12$, one-tailed $){ }^{31}$ This suggests that the desire to impoverish another person below one's own level may be correlated with unhappiness. We do find one significant difference in happiness levels across types: If we look at those individuals who chose the social maximum in Decision 1 and 2, people that also chose $x<600$ in Decision 3 are significantly less happy (Spearman correlation coefficient is $-.267, p=.01$, one-tailed) than people who chose $600 \leq x \leq 1200$.

\section{DISCUSSION}

Perhaps the strongest result we obtain is that there is very little concern about relative payoffs in our simple experimental games. Study 1 and Study 2 both indicate that 
a large majority of participants choose to maximize another person's material payoff, given that their own payoffs are fixed. We find that most people will make a small monetary sacrifice to help another person greatly, but that few people will sacrifice money merely to achieve equality of payoffs.

We also see rather consistent behavior within individual subjects' decisions. Subjects who chose $(625,625)$ in Decision 1 of Study 2 where more likely to choose $(600,600)$ in Decision 2 (Spearman correlation coefficient $0.463, p=.000$, one-tailed) and they were also more likely to choose $x \leq 600$ in Decision 3 (Spearman correlation coefficient $0.270, p=.002$, one-tailed). Moreover, people who sacrificed 25 Pesetas (i.e., chose $(600,600)$ in Decision 2) were also more likely to choose $x<600$ in Decision 3 (Spearman correlation coefficient $0.197, p=.02$, one-tailed).

We do not find a general inverse relationship between a concern for relative payoffs and self-reported happiness. Yet, when a subject's options offer her an identical material payoff $x$, we find that people who choose to assign the other person an amount smaller than $x$ tend to be less happy - in both pertinent decision tasks the differences are significant at $p=.10-.12$. We also observe good internal consistency (as measured by Cronbach's alpha) for our happiness measures and a very definite bias toward believing that one is happier in general than currently; the results from graduate students are particularly striking. There seems to be a maintained belief that things will be (or have been) better. Perhaps this is some sort of a life-cycle phenomenon, so that results would be different for other age groups.

\footnotetext{
${ }^{31}$ Unfortunately, the power of these tests is hindered by only having 9 people in the group for which $\mathrm{x}<$ 600 , but the results parallel those of Study 1 .
} 
By reducing or eliminating differences in monetary reward for the chooser, we are able to spotlight some underlying socialpreferences. Some current utility models of nonpecuniary behavior are based on the presumption that people are bothered by differences in material payoffs. Certainly, envy influences some people in their lives. ${ }^{32}$ However, we find relatively little concern for relative payoffs among the students who participated in our study.

While there are certainly some people motivated by difference aversion, it seems that this is a fairly weak influence. For example, consider Decisions 1 and 2 (Study 2). Of the two-thirds of subjects whose preferences led them to choose $(1200,600)$ over $(625,625)$, nearly all were willing to sacrifice 25 pesetas to implement these preferences. In contrast, of the two-thirds of participants who had either difference-averse or competitive preferences, two-thirds were unwilling to implement them by sacrificing 25 pesetas. The strong difference across Decisions 1 and 2 (Study 1) in the proportion of people not choosing the social maximum $(Z=3.01, p=.001$, one-tailed $)$ indicates that people are also concerned with the minimum payoff, so that a simple altruism model does not appear to explain the results. Instead, people's preferences appear to include a concern for both the total social surplus and the minimum material payoff in the group.

Although subjective well-being is difficult to measure objectively, it is nevertheless an important influence on people's behavior. As it potentially affects many economic decisions, economists have begun to investigate the determinants of happiness. Of necessity, such studies use self-reported data. We do not find that the lack of financial

\footnotetext{
${ }^{32}$ Of course, in the field people can influence their material payoffs, so that this may be a factor.
} 
incentives results in low levels of effort or random responses. We feel that there is considerable validity and scope for this methodology.

Our study is only a start in the process of identifying the relationship of happiness to social preferences. We hope that our results lead to further research on this issue. Extensions of this study and further explorations of the dimensions of social preferences seem valuable, as understanding human motivations is surely useful in predicting and helping to shape economic behavior. 


\section{REFERENCES}

Akerlof, G., "Labor Contracts as Partial Gift-Exchange," 1982, Quarterly Journal of Economics, 97, 543-569.

Akerlof, G. \& J. Yellen, "The Fair Wage-Effort Hypothesis and Unemployment," 1990, Quarterly Journal of Economics, 105, 255-283.

Bachman, J., R. Kahn, F. Davidson \& L. Johnston, Youth in Transition, 1967, Ann Arbor Michigan: Institute for Social Research, Vol. 1.

Bewley, T., "Why not cut pay?," 1998, European Economic Review, 42, 459-490.

Bolton, G. \& A. Ockenfels, "ERC: A Theory of Equity, Reciprocity, and Competition," forthcoming, American Economic Review.

Bradburn, N. \& D. Caplovitz, Reports on Happiness, 1965, Chicago: Aldine.

Bradburn, N. \& O. Noll, The Structure of Psychological Well-Being, 1969, Chicago: Aldine,.

Camerer, C. \& R. Hogarth, "The Effects of Financial Incentives in Experiments: A Review and Capital-Labor-Production Framework," 1999, mimeo.

Charness, G. \& M. Rabin, "Social Preferences: Some Simple Tests and a New Model," 1999, mimeo.

Easterlin, R., “Does Money Buy Happiness?,” 1973, The Public Interest, 30, 3-10.

Easterlin, R., "Does Economic Growth Improve the Human Lot? Some Empirical Evidence," 1974, in Nations and Households in Economic Growth: Essays in Honor of Moses Abramowitz, 89-125, P. David and M. Reder, eds.

Easterlin, R., "Will Raising the Incomes of All Increase the Happiness of All?," 1995, Journal of Economic Behavior and Organization, 27, 35-47.

Engelmann, D. \& M. Strobel, “The False Consensus Effect Disappears if Representative Information and Monetary Incentives Are Given," 1999, mimeo.

Falk, A. \& U. Fischbacher, “A Theory of Reciprocity,” 1999, mimeo.

Fehr, E. \& K. Schmidt, “A Theory of Fairness, Competition, and Cooperation,” Quarterly Journal of Economics, 1999, 114, 817-868.

Fordyce, M., "A Review of Research on the Happiness Measures: A Sixty Second Index of Happiness and Mental Health," 1988, Social Indicators Research, 20, 355 - 381. 
Frey, B. \& A. Stutzer, "Measuring Preferences by Subjective Well-Being,” 1999, mimeo.

Frank, R., Choosing the Right Pond, 1985, Oxford: Oxford University Press.

Frank, R., "The Frame of Reference as a Public Good," 1997, Economic Journal, 107, 1832-1847.

Glasnapp, D. \& J. Poggio, Essentials of Statistical Analysis for the Behavioral Sciences, 1985, Columbus: Merrill.

Güth, W., R. Schmittberger \& B. Schwarze, "An Experimental Analysis of Ultimatum Bargaining,” 1982, Journal of Economic Behavior and Organization, 3, 376-388.

Jacobsen, E. \& A. Sadrieh, "Experimental Proof for the Motivational Importance of Reciprocity," University of Bonn, Discussion Paper No. B-386, 1996

Konow, J. \& J. Earley, “The Hedonic Paradox: Is Homo Economicus Happier?,” 1999, mimeo.

Liebrand, W., "The Effect of Social Motives, Communication, and Group Size on Behaviour in an N-person Multi Stage Mixed Motive Game," European Journal of Social Psychology, 1984, 14, 239-264.

Long, J., J. Lynch, N. Machiran, S. Thomas \& K. Malinow, "The Effect of Status on Blood Pressure during Verbal Communication," 1982, Journal of Behavioral Medicine, 5, 165-171.

Lyubomirsky, S. \& L. Ross, "Hedonic Consequences of Social Comparison: A Contrast of Happy and Unhappy People," 1997, Journal of Personality and Social Psychology, 73, 1141-1157.

McClintock, C. \& W. Liebrand, "Role of Interdependency Structure, Individual Value Orientation, and Another's Strategy in Social Decision Making: A Transformational Analysis," 1988, Journal of Personality and Social Psychology, 55, 396-409.

Mullen, B., J. Atkins, D. Champion, C. Edwards, D. Hardy, J. Story \& M. Venderklok, "The False Consensus Effect: A Meta-Analysis of 115 Hypothesis Tests," 1985, Journal of Experimental Social Psychology, 21, 263-283.

Offerman, T., J. Sonnemans \& A. Schram, "Value Orientations, Expectations and Voluntary Contributions in Public Goods," Economic Journal, 1996, 106, 817-845.

Oswald, A., "Happiness and Economic Performance," 1997, Economic Journal, 107, 1815-1831. 
Reiser, M., R. Reeves \& J. Armington, "Effect of Variations in Laboratory Procedures and Experimenter upon the Ballistocardiogram, Blood Pressure, and Heart Rate in Healthy Young Men," 1955, Psychosomatic Medicine, 17, 185-199.

Ross, L., D. Greene \& P. House, "The "False Consensus Effect": An Egocentric Bias in Social Perception and Attribution Processes, "1977, Journal of Experimental Social Psychology, 13, 279-301.

Sen, A., "Behavior and the Concept of Preferences," 1972, Economica, 40, 241-259.

Sen, A., "The Standard of Living," 1986, in Tanner Lectures on Human Values, Vol. VII, S. McMurrin, ed.

Selten, R. \& A. Ockenfels, “An Experimental Solidarity Game, ” 1993, Journal of Economic Behavior and Organization, 34, 517-539

Siegel, S. \& N. Castellan, Jr., Nonparametric Statistics for the Behavioral Science, 1988, New York: McGraw-Hill.

Veenhoven, R., Happiness in Nations: Subjective Appreciation of Life in 56 Nations 1946-1992, 1993, Rotterdam: Erasmus University Press.

Wilson, W., "An Attempt to Determine Some Correlates and Dimensions of Hedonic Tone, " Unpublished Ph.D. Dissertation, Northwestern University, 1960. 


\section{APPENDIX A - Study 1}

\section{General Instructions}

Thank you very much for participating in this experiment. The object of this session is to study how people make decisions. You will receive a show-up fee of 200 pesetas. You will receive additional money based on the decisions made in the session. It is very important that you do not talk to each other during the experiment. If you have any questions, please raise your hand and one of the instructors will attend you.

There are cards with numbers on them in the box that we are now passing around. Please choose one. This number will serve as your identification number. Do not show it to anyone except the instructors.

In this experiment there will be participants of type " $A$ " and "B". If you received an odd number, please stay in this room. In this case, you are a type "A" participant. If you received an even number, please follow the instructor into another room. In this case, you are a type "B" participant.

[Students picked numbers and left the room accordingly].

\section{[Instructions for the Live group]}

All participants in this room will be of type B. Participants in the other room are all type A players and will not make any decisions. They are given exactly the same instructions as you are, so they know what you have been asked to do.

Please make your choice for the following games [these are presented separately]:

\section{Decision 1}

Choose between option B1 and B2:

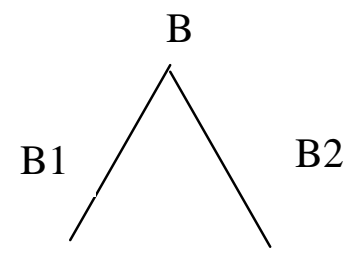
A 900
$600 \quad$ A
B 600
$600 \quad \mathrm{~B}$

My decision is:

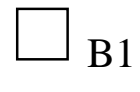




\section{Decision 2}

Choose between option B1 and B2!

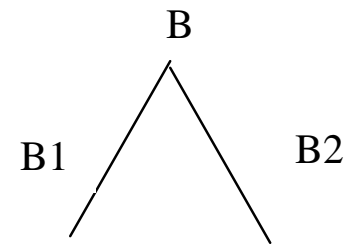

$\begin{array}{llll}\text { A } & 400 & 600 & \text { A } \\ \text { B } & 600 & 600 & \text { B }\end{array}$

My decision is:

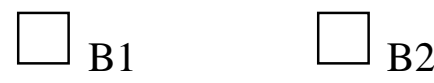

\section{[Instructions for the Dead group]}

In this room all participants are type A. As such you do not have a choice in this decision task, but we would nevertheless like to know what you think the others are doing. In the following you will see the decision problem of the participants of type B, which are in the other room. They can choose between B1 and B2.

\section{Decision 1}

This is the decision that players of type B have to make. They can choose between option $\mathrm{B} 1$ and $\mathrm{B} 2$.

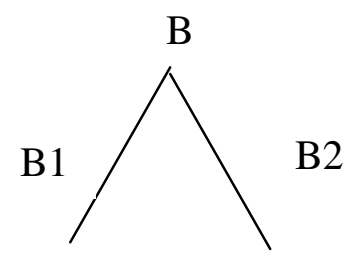
A 900
$600 \quad$ A
B 600
$600 \quad \mathrm{~B}$

What do you think is the percentage of participants choosing B1 or B2? (The sum of both percentages has to sum up to $100 \%$.)

$$
\text { B } 1 \ldots \ldots \% \text { B } 2 \ldots \ldots \%
$$

If you were a type B person, what would you choose? 
My decision would be:

B1

B2

\section{Decision 2}

This is the decision that players of type B have to make. They can choose between option $\mathrm{B} 1$ and $\mathrm{B} 2$.

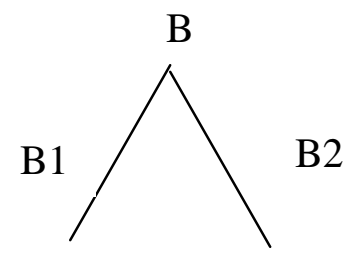
A 400
600 A
B 600
600 B

What do you think is the percentage of participants choosing B1 or B2? (The sum of both percentages has to sum up to $100 \%$.)

$$
\text { B } 1 \ldots \ldots \% \text { B } 2 \ldots \ldots \%
$$

If you were a type B person, what would you choose?

My decision would be:

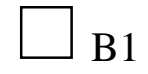

$\mathrm{B} 2$

Before you receive your payments, we would like to ask you to complete the following questionnaire. Please respond as accurately as possible, since this is also part of our investigation. Thank you very much. 


\section{Part I}

Use the list below to answer the following question: In general, how happy or unhappy do you usually feel? Check the one (and only one) statement that best describes your average happiness.

- Extremely happy (feeling ecstatic, joyous, fantastic!)

口 Very happy (feeling really good, elated!)

- Pretty happy (spirits high, feeling good.)

口 Mildly happy (feeling fairly good and somewhat cheerful.)

- Slightly happy (just a bit above neutral.)

- Neutral (not particularly happy or unhappy.)

- Slightly unhappy (just a bit below neutral.)

- Mildly unhappy (just a little low.)

口 Pretty unhappy (somewhat "blue", spirits down.)

- Very unhappy (depressed, spirits very low.)

口 Extremely unhappy (utterly depressed, completely down.)

Consider your emotions a bit further. On the average, what percent of time do you feel happy? What percent of time do you feel neutral (neither happy nor unhappy)? What percent of time do you feel unhappy? Write down your best estimates, as well as you can, in the spaces below. Make sure the three figures add up to $100 \%$.

On the average:

The percent of time I feel happy

The percent of time I feel neutral

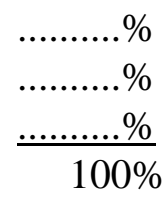

The percent of time I feel unhappy $\frac{\ldots \ldots \ldots . . . \%}{100 \%}$

Part II

What do you think about the happiness of an average person? Use the list below to answer the following question: In general, how happy or unhappy does an average person feel? Check the one (and only one) statement that best describes the happiness of an average person.

口 Extremely happy (feeling ecstatic, joyous, fantastic!)

- Very happy (feeling really good, elated!)

口 Pretty happy (spirits high, feeling good.)

- Mildly happy (feeling fairly good and somewhat cheerful.)

- Slightly happy (just a bit above neutral.)

口 Neutral (not particularly happy or unhappy.)

- Slightly unhappy (just a bit below neutral.) 
- Mildly unhappy (just a little low.)

口 Pretty unhappy (somewhat "blue", spirits down.)

口 Very unhappy (depressed, spirits very low.)

口 Extremely unhappy (utterly depressed, completely down.)

Compared to an average person, how would you describe yourself in terms of your average happiness? Please check the one (and only one) statement that best describes your average happiness compared to that of an average person.

a Much more happy than the average person

- Slightly more happy than the average person

- Just about as happy as the average person

- Not quite as happy as the average person

- Much less happy than the average person

\section{$\underline{\text { Part III }}$}

Did anything make you happy today? (Think of friends, relatives, money, university performance, presents, news etc.) Please check either of the boxes below.

Yes. $\quad$ No.

Did anything make you unhappy today? (Think of friends, relatives, money, university performance, presents, news etc.) Please check either of the boxes below.

Yes. $\quad$ No.

How do you feel right now? Please check the one (and only one) box that best describes your momentary level of happiness.

口 Extremely happy (feeling ecstatic, joyous, fantastic!)

- Very happy (feeling really good, elated!)

口 Pretty happy (spirits high, feeling good.)

- Mildly happy (feeling fairly good and somewhat cheerful.)

- Slightly happy (just a bit above neutral.)

- Neutral (not particularly happy or unhappy.)

口 Slightly unhappy (just a bit below neutral.)

口 Mildly unhappy (just a little low.)

口 Pretty unhappy (somewhat "blue", spirits down.)

- Very unhappy (depressed, spirits very low.)

口 Extremely unhappy (utterly depressed, completely down.) 


\section{APPENDIX B - Study 2}

\section{INSTRUCTIONS}

Thank you very much for participating in this experiment. The object of this investigation is to study how people make decisions. If you have any questions, please raise your hand and an instructor will attend you. From now on until the end of the experiment you will not be allowed to communicate with any other participant.

In this session we will divide the group of participants into two rooms. After having read the instructions, half of the participants will remain in this room and the other half will go to room L204.

Before we start the experimental session, please answer the following questions. Your responses will not effect your payments, but please be as precise as possible since this is also part of our investigation.

For each of the following statements and/or questions, please circle the point on the scale that you feel is most appropriate in describing you.

1. In general, I consider myself:

$\begin{array}{lllllrr}\mathbf{1} & \mathbf{2} & \mathbf{3} & \mathbf{4} & \mathbf{5} & \mathbf{6} & \mathbf{7} \\ \text { not a very } & & & & & \text { a very } \\ \text { happy } & & & & \text { happy } \\ \text { person } & & & & \text { person }\end{array}$

2. Compared to most of my peers, I consider myself:

$\begin{array}{llllllr}1 & 2 & 3 & 4 & 5 & 6 & 7 \\ \text { less } & & & & & & \text { more } \\ \text { happy } & & & & & & \text { happy }\end{array}$

3. Some people are generally very happy. They enjoy life regardless of what is going on, getting the most out of everything. To what extent does this characterization describe you?

$\begin{array}{llllllr}\mathbf{1} & \mathbf{2} & \mathbf{3} & \mathbf{4} & \mathbf{5} & \mathbf{6} & \mathbf{7} \\ \begin{array}{l}\text { not at } \\ \text { all }\end{array} & & & & & \text { a great } \\ \text { deal }\end{array}$

4. Some people are generally not very happy. Although they are not depressed, they never seem as happy as they might be. To what extent does this characterization describe you? 
You will find a total of 5 pages in the package we have distributed. It is very important that you consider each page one at a time and leave the rest in their reverse order.

You will receive 200 pesetas for participating in this experiment. Additionally, you can earn more money during the session. This additional amount, plus the 200 Ptas., will be paid to you privately at the end of the experiment.

There will be three decisions to make. Each participant in this room will be paired with another participant in the other room. Nobody knows the identity of the persons he/she is matched with.

There are two types of participants in this experimental session; type $\mathbf{A}$ and type $\mathbf{B}$. Only type B subjects make decisions. At this moment, we do not know if participants in this room are type A or B.

After the session we will role a die to determine which of the decisions made will be implemented for payoffs. For now, presume that you are type B, so that the person you are matched with is type A. If, at the end it turns out that you are selected to be of type B, then your decisions will determine your payoff as well as that of the person you are matched with. On the other hand, if it turns out that the person with whom you are matched is type $\mathrm{B}$, then it would ve the decision of the other person that determines your payoffs, rather than your decision.

\section{Decision 1}

Choose between option B1 and B2:

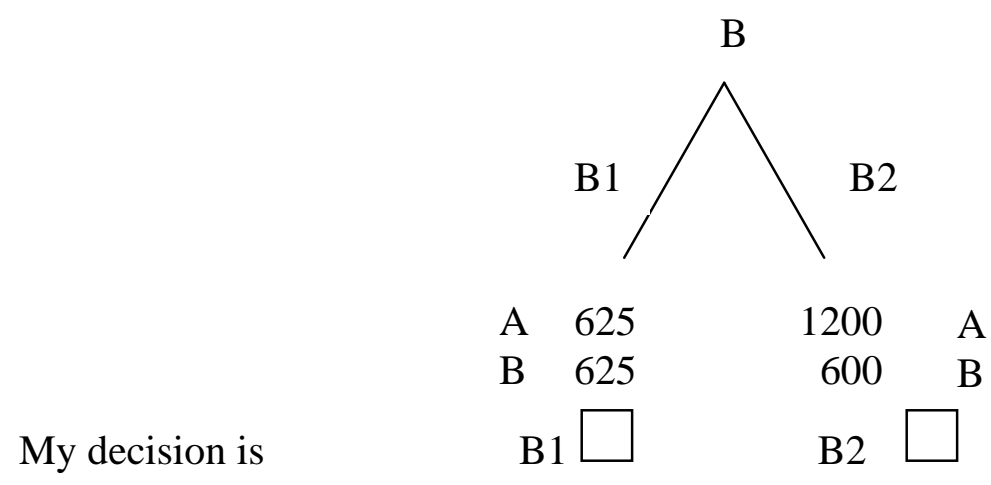




\section{Decision 2}

Choose between option B1 and B2:

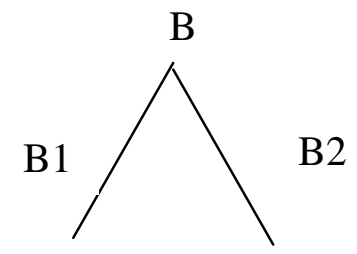
A 1200
$600 \quad \mathrm{~A}$
B 625
$600 \quad \mathrm{~B}$

My decision is

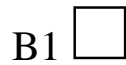

B2 $\square$

\section{Decision 3}

Choose between option B1 and B2:

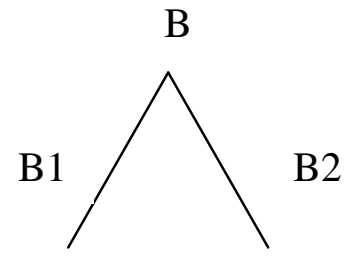
A 600
$\mathrm{x} \quad$ A $(300 \leq \mathrm{x} \leq 1200)$
B 600
$600 \quad \mathrm{~B}$

My decision is

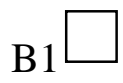

B2 and $\mathrm{I}$ choose $\mathrm{x}=$

Before you will receive your payment it is necessary that you read the following list of words. You will have three minutes to memorize them before the instructor collects the list. Please write then 10 words (and only 10) down which you remember.

frightful, joyful, glorious, malicious, discouraged, magnificent, fortunate, amiable, depressed, low-spirited, pleased, enjoyable, marvelous, unhealthy, satisfied, repulsive, grateful, disgusting, nice, revolting, wretched, happy, sad, distracted 


\section{APPENDIX C}

Table C1 - Spearman Correlations - Questionnaire Responses (Study 1)

\begin{tabular}{|c|c|c|c|c|c|c|c|}
\hline & Gen. & Friends & \%happy & \%unhappy & Comp. & Pos_words & Neg_words \\
\hline General & - & $\begin{array}{l}.621 * * \\
(.000)\end{array}$ & $\begin{array}{l}.526 * * \\
(.000)\end{array}$ & $\begin{array}{c}.542 * * \\
(.000)\end{array}$ & $\begin{array}{l}.823 * * \\
(.000)\end{array}$ & $\begin{array}{l}.240 * * \\
.006)\end{array}$ & $\begin{array}{c}.240 * * \\
(.006)\end{array}$ \\
\hline Friends & & - & $\begin{array}{l}.413 * * \\
(.000)\end{array}$ & $\begin{array}{c}.400 * * \\
(.000)\end{array}$ & $\begin{array}{l}.719 * * \\
(.000)\end{array}$ & $\begin{array}{l}.154 \\
(.055)\end{array}$ & $\begin{array}{l}-.136 \\
(.080)\end{array}$ \\
\hline \%happy & & & - & $\begin{array}{c}-.340^{* * *} \\
(.000) \\
\end{array}$ & $\begin{array}{l}.762 * * \\
(.000) \\
\end{array}$ & $\begin{array}{c}.102 \\
(.146) \\
\end{array}$ & $\begin{array}{l}-.088 \\
(.183) \\
\end{array}$ \\
\hline \%unhappy & & & & - & $\begin{array}{c}-.742^{* *} \\
(.000)\end{array}$ & $\begin{array}{l}-.207^{*} \\
(.016)\end{array}$ & $\begin{array}{l}.196^{*} \\
(.021)\end{array}$ \\
\hline Composite & & & & & - & $\begin{array}{l}.191 * \\
(.024)\end{array}$ & $\begin{array}{l}-.174 * \\
(.036)\end{array}$ \\
\hline $\begin{array}{l}\text { Positive } \\
\text { words }\end{array}$ & & & & & & - & $\begin{array}{c}-.944 * * \\
(.000)\end{array}$ \\
\hline $\begin{array}{c}\text { Negative } \\
\text { Words }\end{array}$ & & & & & & & - \\
\hline
\end{tabular}

Note: $p$-values are given in parenthesis (** indicates significance on a level of .01 (one-tailed), and enotes a significance level of .10 (one-tailed))

Table C2 - Spearman Correlations - Questionnaire Responses (Study 1)

\begin{tabular}{|c|c|c|c|c|c|}
\hline & Gen. & Mom. & Good_h & Bad_h & Comp_Med \\
\hline \multirow{2}{*}{ General } & - & $\begin{array}{c}.666^{* *} \\
(.000)\end{array}$ & $\begin{array}{c}.344^{* *} \\
(.007)\end{array}$ & $\begin{array}{c}-.194 \\
(.135)\end{array}$ & $\begin{array}{c}.683^{* *} \\
(.000)\end{array}$ \\
\hline \multirow{2}{*}{ Momentary } & & - & $\begin{array}{c}.375^{* *} \\
(.003)\end{array}$ & $\begin{array}{c}-.272^{* *} \\
(.034)\end{array}$ & $\begin{array}{c}.550^{* *} \\
(.000)\end{array}$ \\
\hline \multirow{2}{*}{ Good_h } & & & - & $\begin{array}{c}.206 \\
(.111)\end{array}$ & $\begin{array}{c}.201 \\
(.121)\end{array}$ \\
\hline \multirow{2}{*}{ Bad_h } & & & & - & $-\begin{array}{c}.061 \\
.639)\end{array}$ \\
\hline Comp_Med & & & & & - \\
\hline
\end{tabular}

Note: $p$-values are given in parenthesis (** indicates significance on a level of .01 (one-tailed), and * denotes a significance level of .10 (one-tailed), Good_h $=1$, if the person reported that something made her happy that day, Bad_h $=1$ if the person reported something made her unhappy that day, Comp_Med is her response to how she compares herself to an average person) 